\title{
Editorial
}

\section{Primary Amenorrhea and its evaluation}

\section{Gedam DS}

Dr D Sharad Gedam, Editor, Obs gyne Review: Journal of Obstetrics and Gynecology \& Professor, L N Medical College, Bhopal, MP, India

Address for correspondence: Dr D Sharad Gedam, Email: editor.joog@gmail.com

\begin{abstract}
Primary and secondary Amenorrhea is most common complaint in Obstetrics and Gynaecology. Evaluation of these patients for cause and treatment is essential.
\end{abstract}

Keywords: Primary Amenorrhea, menarche, Mullerian agenesis

Primary Amenorrhea is defined as failure to achieve menarche. Evaluation should be undertaken if there is no pubertal development by 13 years of age, if menarche has not occurred five years after initial breast development, or if the patient is 15 years or older $[1,2,3]$. Secondary Amenorrhea is defined as cessation of regular menstruation for 3 months or irregular menstruation for 6 months [1,2]. Normal menstruation last for 21-35 days.

Primary Amenorrhea is most commonly caused by chromosomal disorder which leads primary ovarian failure (for example Turners syndrome) and structural abnormality (i.e. Mullerian agenesis). Secondary Amenorrhea is caused by polycystic ovarian syndrome, hypothalamic amenorrhea, hyperprolactinemia, or primary ovarian insufficiency.

During evaluation it is important to evaluate for anatomical defect (outflow tract obstruction), Primary ovarian failure, hypothalamic- pituitary malfunction and endocrinal gland involvement. Patients should be asked about eating and exercise patterns, changes in weight, previous menses (if any), medication use, chronic illness, presence of galactorrhea, and symptoms of androgen excess, abnormal thyroid function. Pregnancy test should be performed in all cases. Family history should include age at menarche and presence of chronic disease. Although it is normal for menses to be irregular in the first few years after menarche [4].

History

It is always important to take proper history to rule out pregnancy. All the causes of secondary amenorrhea to be ruled out in primary amenorrhea.
The physician should measure the patient's height, weight, and body mass index, and perform thyroid palpation and Tanner staging. Breast development is an excellent marker for ovarian estrogen production. Acne, virilization, or hirsutism may suggest hyperandrogenemia. Genital examination may reveal virilization, evidence of an outflow tract obstruction, or a missing or malformed organ. Thin vaginal mucosa is suggestive of low estrogen. Dysmorphic features such as a webbed neck or low hairline may suggest Turner syndrome [5].

\section{Evaluation}

Initial evaluation includes pregnancy test and LH, FSH, Prolactin, Thyroid function test measurement. If virilising features are there Testosterone level should be measure. Karyotyping should be done if syndromic disorder is suspected. Serum estradiol level measurement should be done if there is no breast development. Evdences for chronic disorder like Complete blood count, ESR \& CRP should be measured [5]. Further testing includes USG for Internal organ of female genital tract \& MRI if pituitary tumour is suspected.

Anatomical abnormalities include Mullerian agenesis other causes are imperforated hymen \& transverse vaginal septum. Primary ovarian insufficiency is characterized by Postmenopausal FSH level. The ovaries require physiologic stimulation by pituitary gonadotropins for appropriate follicular development and estrogen production. Functional hypothalamic amenorrhea occurs when the hypothalamic-pituitaryovarian axis is suppressed due to an energy deficit 


\section{Editorial}

stemming from stress, weight loss (independent of original weight), excessive exercise, or disordered eating.

Prolactin levels can be increased due to drugs, pituitary diseases, Hypothyroidism. Severe hyperthyroidism are more likely to be responsible for amenorrhea rather than Mild to moderate Hyperthyroidism or hypothyroidism.

\section{References}

1. Practice Committee of American Society for Reproductive Medicine. Current evaluation of amenorrhea. Fertil Steril. 2008;90(5 suppl):S219-S225.

2. Speroff L, Fritz MA. Clinical Gynecologic Endocrinology and Infertility. 7th ed. Philadelphia, Pa.: Lippincott Williams \& Wilkins: 2005:401-464.
3. Euling SY, Herman-Giddens ME, Lee PA, et al. Examination of US puberty-timing data from 1940 to 1994 for secular trends: panel findings. Pediatrics. 2008;121(suppl 3):S172-S191.

4. Diaz A, Laufer MR, Breech LL; American Academy of Pediatrics Committee on Adolescence; American College of Obstetricians and Gynecologists Committee on Adolescent Health Care. Menstruation in girls and adolescents: using the menstrual cycle as a vital sign. Pediatrics. 2006;118(5):2245-2250.

5. Gordon CM. Clinical practice. Functional hypothalamic amenorrhea. $N$ Engl $J$ Med. 2010;363(4):365-371.

\section{How to cite this article?}

Gedam DS. Primary Amenorrhea and its evaluation. Obs Rev: J obstet Gynecol 2015;1(1):1-2.

doi:10.17511/joog.2015.i01.01. 